\title{
Lateral epicondylosis
}

\author{
Yibo Li MD, Fangwei Liu MD, Armin Badre MD MSc
}

Cite as: CMAJ 2022 February 22;194:E257. doi: 10.1503/cmaj.211047

1

Lateral epicondylosis (tennis elbow) is a degenerative, noninflammatory condition of the common extensor origin at the lateral epicondyle of the elbow

Tennis elbow has a prevalence of $1 \%-3 \%$, peaking at age $35-50$ years. ${ }^{1}$ It is associated with smoking and with a combination of repetitive and forceful manual activities. ${ }^{2}$

\section{The diagnosis is clinical based on lateral elbow pain and epicondyle tenderness}

Provocative tests include pain with resisted extension of the long fingers or wrist when the elbow is extended. Pain distal to the epicondyle suggests radial tunnel syndrome and warrants orthopedic referral. Clinicians should obtain radiographs for patients with loss of range of motion, locking or catching of the elbow to assess for osteoarthritis and osteochondritis dissecans. Ultrasonography and magnetic resonance imaging have variable sensitivity and specificity, and are not routinely required. ${ }^{1}$

\section{3}

\section{Symptoms of tennis elbow are managed with physiotherapy} and anti-inflammatory agents

Eccentric strengthening of the common extensor origin (Appendix 1, available at www.cmaj.ca/lookup/doi/10.1503/cmaj.211047/tab-related -content) reduces pain and improves function and grip strength. ${ }^{2}$ Topical nonsteroidal anti-inflammatory drugs (NSAIDs) reduce pain (number needed to treat $=7$ ) with few adverse effects, but oral NSAIDs provide unclear benefit with a risk of gastrointestinal adverse effects. ${ }^{3}$

\section{4}

\section{Corticosteroid injections should be avoided}

Corticosteroid injections provide only short-term pain relief and result in lower rates of symptom resolution or improvement (number needed to harm $[\mathrm{NNH}]=8)$ and greater risk of symptom recurrence $(\mathrm{NNH}=2)$ than placebo injections at 1 year. ${ }^{4}$ The efficacy of platelet-rich plasma is unclear, given variation in its preparation and lack of superiority to placebo in underpowered studies. ${ }^{5}$

\section{Referral for surgery should be considered after 6 months of failed nonoperative management}

Tennis elbow is usually self-limiting, and $90 \%$ of patients recover within 1 year. Those who do not respond after 6 months of nonoperative treatment are likely to have a prolonged disease course of more than 2 years and are potential candidates for surgery. ${ }^{6}$ Open, arthroscopic or percutaneous débridement of the common extensor origin has been shown to improve pain and function scores, with good-to-excellent outcomes in $80 \%$ of patients. ${ }^{6}$

\section{References}

1. Karanasios S, Korakakis V, Moutzouri M, et al. Diagnostic accuracy of examination tests for lateral elbow tendinopathy (LET): a systematic review. J Hand Ther 2021 Feb 27;S08941130(21)00039-9. doi: 10.1016/j.jht.2021.02.002. [Epub ahead of print].

2. Culliane FL, Boocock MG, Trevelyan FC. Is eccentric exercise an effective treatment for lateral epicondylitis? A systematic review. Clin Rehabil 2014;28:3-19.

3. Pattanittum P, Turner T, Green S, et al. Non-steroidal antiinflammatory drugs (NSAIDs) for treating lateral elbow pain in adults. Cochrane Database Syst Rev 2013;(5):CD003686.

4. Coombes BK, Bisset L, Brooks P, Khan A, et al. Effect of corticosteroid injection, physiotherapy, or both on clinical outcomes in patients with unilateral lateral epicondylalgia: a randomized controlled trial. JAMA 2013;309:461-9.

5. Simental-Mendia M, Vilchez-Cavazos F, Alvarez-Villalobos N, et al. Clinical efficacy of platelet-rich plasma in the treatment of lateral epicondylitis: a systematic review and meta-analysis of randomized placebo-controlled clinical trials. Clin Rheumatol 2020;39:2255-65

6. Sanders Jr TL, Kremers HM, Bryan AJ, et al. The epidemiology and health care burden of tennis elbow: a population-based study. Am J Sports Med 2015;43:1066-71.

\section{Competing interests: None declared.}

This article has been peer reviewed.

Affiliations: Departments of Surgery (Li, Badre) and Family Medicine (Liu), and Western Upper Limb Facility (Badre), University of Alberta, Edmonton, Alta.

Content licence: This is an Open Access article distributed in accordance with the terms of the Creative Commons Attribution (CC BY-NC-ND 4.0) licence, which permits use, distribution and reproduction in any medium, provided that the original publication is properly cited, the use is noncommercial (i.e., research or educational use), and no modifications or adaptations are made. See: https://creativecommons. org/licenses/by-nc-nd/4.0/

Correspondence to: Yibo Li, li4@ualberta.ca

CMAJ invites submissions to "Five things to know about ..." Submit manuscripts online at http://mc. manuscriptcentral.com/cmaj 